\title{
CONCEPTUAL MODEL OF BUDGETARY ACTIVITY ON FIRMS PERFORMANCE: MALAYSIAN SMEs CASE STUDY
}

\author{
Edward Wong Sek Khin, Cheok Mui Yee and Kamisah Ismail
}

\begin{abstract}
This study examines the relationship of management accounting budgetary activities impacting on firm's performance. The purpose of this paper is to provide evidence on how budgetary goals influencing a firm's performance outcomes, whether positively or negatively. The result also demonstrated that the improvement of the budgetary control system would be essential for obtaining an accurate budget. Therefore, it is possible that budget makers in firms are likely to provide decision-makers with a basis for measuring efficiency, identifying problems, and controlling costs. It also serves as a control tool for evaluating the performance of the members of an organization.
\end{abstract}

Keywords: Budgetary goal, budgetary participation, budgetary evaluation JEL Classification: M11, M41, L25

\section{Introduction}

This paper is centred on the issue of budgetary goals. Thus, many organizations have to constantly strive to maximize their effectiveness and efficiency in the budgetary control process in order to maintain their competitive advantage. This is because having a proper budgetary control system allows companies to improve their managerial attitude and performance within the organization and provide the organization with useful information to tackle the challenges faced. In view of this, this study investigates whether budgetary goals have an association with organizational performance. However, industry practitioners may also offer insights, regardless of whether they are for profit or not for profit organizations, in order to reduce management-sourced errors when building budgeting goal activities.

\subsection{Research gaps}

Although the characteristics of budgeting have been studied previously (Collins, 1978) in relation to performance, some potentially important relationships remain unanswered (Kenis, 1979). Particularly, although Kenis's (1979) model did not identify any mediating situational variable, he claimed that factors, such

Corresponding author: Dr Edward Wong Sek Khin is an Associate Professor in the Faculty of Business and Accountancy, University of Malaya, email: edwardwong@um.edu.my. Cheok Mui Yee is a PhD candidate in the Faculty of Business and Accountancy. Dr Kamisah Ismail is a Senior Lecturer in the Faculty of Business and Accountancy, University of Malaya. 
as personality and the needs of managers, goal acceptance, reward expectancy, and some organisational and environmental variables, are capable of influencing the relationship studied in his model.

In addition, Chong and Johnson (2007) found that task uncertainty is an important antecedent of budgetary participation. Employees who are low in analysability tend to participate more in the budgeting process when they require additional job-relevant information. However, their studies did not take into account other potential antecedents of budgetary participation, such as perceived environmental uncertainty (Chong and Chong, 1997; Shield and Shield, 1998).

Chong and Johnson (2007) also confirmed that participation in setting the budget influences the budget goal level and motivation (i.e. budget goal acceptance and budget goal commitment) of subordinates, which, ultimately, enhances their job performance. However, they did not include other potential intervening variables, such as perception of fairness, which may affect the behaviour and attitude of subordinates. Wentzel (2002) provided an insight into examining the influence of the perception of fairness on performance. Her study provided evidence that the perception of fairness mediates the relation between the level of budget participation and goal commitment, in which goal commitment mediates the relation between the perception of fairness and performance. Her study was found to have a gender bias, which required extending the external validity, and it was conducted with the use of a single firm, thus limiting the generalisability of the findings. Also, her model was designed with a focus on the issue of fairness during times of downsizing or scarce resources. Although this is not a necessary condition for her proposed model, it raises the question of whether the perception of fairness is also salient during times of growth and expansion, especially in the context of SMEs in Malaysia, which are in the stage of expansion. Thus, further examination is required.

Erez et al. (1985) concluded that participation affects performance through its effect on goal acceptance whereby performance also increases. Participation in goal setting enhances goal acceptance when individuals are presented with goals that they initially reject because they perceive them as being unreasonable or too difficult. However, their study failed to explain how such a perception influences people in terms of accepting or rejecting the goals (Renn 1998). In addition, only participation was examined in their study, and they encouraged other factors, such as feedback and evaluation (Kenis, 1979), which may influence performance and goal acceptance, and, hence, should also be examined. Feedback and evaluation may enhance or impede the motivation of individuals to perform, and, thus, play an important role in enriching the goal setting model (Erez et al., 1985).

Renn (1998) examined the effect of participation on task performance using the mediating roles of goal acceptance and procedural justice. He found that participation is indirectly and positively related to task performance through goal acceptance. Participation is positively related to the perception of 
procedural justice regarding the goal-setting programme; however, the perception of procedural justice is not related to task performance. He explained that this could be due to the lack of support from distributive justice, which may nullify the effect of procedural justice. Thus, the effect of distributive justice perception on such a relationship needs to be examined further.

Lau et al. (2008) indicated that the fairness of the performance evaluation procedures has a significant total effect on the job satisfaction of subordinates, albeit the total effect is mainly indirect. However, their studies showed that the relative small size of this effect is only 0.062 as compared to its total indirect effect of 0.434 , which is worth exploring further for a more comprehensive explanation.

Mohamed et al. (2012) concluded that the consideration of procedural justice is important in the context of critical supervisory feedback, as the respondents who attribute critical comments to the supervisor's negative behavioural dispositions are less likely to acknowledge the content of the criticism. However, their findings are taken as equivocal evidence of the proposed causal process that requires further examination, especially as distributive justice was not taken into account in this study.

\section{Literature review}

\subsection{Budgetary goal characteristics}

A budget is an accounting tool that sets the cost and revenue goals for the responsibility centres within an organization, and is a measurement tool for the control, coordination, communication, performance and motivation. Thus, dissemination of knowledge about budgetary goals should be carefully planned by upper management and explicitly understood by members of organizations so that they can implement an effective budget. In other words, the proper use of budgets may result in a useful managerial tool. However, conversely, the improper application of a budget can lead to dysfunctional behaviour and raise negative attitudes within an organization. Hence, gaining an understanding of the characteristics of budgetary goals, may lead to an accurate budget - directly and through organizational commitment - and lead to improved performance (Nouri and Parker, 1998). The concept of how budget goals are determined can be traced back to the budgeting style of management, which includes the participation of management, the feedback received within the organization, and how budgets are used for the evaluation of performance (Kenis, 1979).

\subsection{Budgetary participation}

Budgetary participation refers to the extent to which those concerned with the budget participate in its preparation and influence the budget goals of their responsibility centres (Kenis, 1979). Active participation in the setting of budgetary goals encourages employees to have clearly defined goals, and 
promotes a willingness to accept the goals as part of their responsibility, and a desire to strive towards their accomplishment.

\subsection{Budgetary feedback}

Employees need to be informed and provide feedback as to whether or not budget goals have been achieved, as it is an important motivational variable (Kenis, 1979). If they are kept in the dark and do not know the results of their efforts, there is no sense of their success for achieving higher goals, or, on the other hand, have a sense of failure, which would lead to new goals to improve their future performance.

\subsection{Budgetary evaluation}

Budgetary evaluation refers to the extent to which budget variances are traced back to individual departmental heads and are used in evaluating their performance (Kenis, 1979). The way in which budgets are used in the evaluation of performance tends to influence the behaviour, attitude and performance of employees. For instance, a punitive approach may lead to lower motivation and a negative attitude, whereas a supportive approach may result in a positive attitude and behaviour.

\subsection{Budgetary performance}

Budgetary performance is widely adopted to examine how well organizations perform in their implementation of budgets. The performance of a budget is also associated with a relatively different set of budgeting characteristics, such as choice of target difficulty, amount of participation in the budgeting process, and amount of emphasis on meeting budget targets.

Hansen and Stede (2004) concluded that the reason-to-budget performance on operational planning, performance evaluation, communication of goals, and strategy formation is positively associated with overall budget satisfaction. However, some studies (Tsui, 2001; Jermias and Setiawan, 2008) found that performance outcome may not be outlined when it is being operated for multiple purposes, particularly in planning and evaluation. They believe that the evaluation of the performance of a budget differs depending on the purpose of the budgetary control system of the organization.

\subsection{Perceived environmental uncertainty (PEU)}

The concept of perceived environmental uncertainty (PEU) that is applied as a contingency variable is widely adopted in business-related fields, such as accounting. The two most common models discussed are those of Duncan (1972) and Milliken (1987, 1990).

Duncan (1972) proposed that uncertainty is a result of the lack of information regarding environmental factors, not knowing the outcome of a decision and its 
losses if incorrect, and the inability to assign probabilities to environmental factors.

Milliken (1987, 1990) classified uncertainty into a different set of categories of uncertainty: state, effect and response. The first kind of uncertainty, 'state uncertainty', is about managers lack of understanding in terms of how elements of the environment may be changing, that is, the perception of environmental unpredictability. The second kind of uncertainty, 'effect uncertainty', occurs when the ability of managers to predict the impact of events on their organisation is limited. The final category, 'response uncertainty', occurs in the absence of knowledge concerning available response options or as a result of the inability to predict the consequences of a given organisational response. The nature of these three kinds of uncertainty is very different, and failure to distinguish between them may lead to myriad conflicting research findings.

\subsection{Perception of fairness}

The organisational justice (fairness) theory suggests two forms of fairness procedural fairness and distributive fairness. The procedural fairness theory suggests that people are concerned with the means or processes by which decisions are made and the outcomes determined. As long as the means and processes are considered fair, people are satisfied. On the other hand, the distributive fairness theory proposes that with respect to decisions involving allocation, people are primarily concerned with and affected by the fairness of the outcomes. As long as the outcome is fair (equitable), people are satisfied (Lau and Tan, 2005).

\subsection{Goal acceptance and goal commitment}

Leifer and McGannon (1986) defined goal acceptance as an attitude reflecting the reasonableness and personal acceptability of an assigned goal. They also defined goal commitment as the determination to achieve a goal, and the willingness to put forth effort to attain a goal. Based on the goal setting theory, it is assumed that goals represent an end state towards which a person strives, and serve as immediate regulators of action. The most significant finding is that specific and hard goals result in better task performance, given that the goals are accepted. Also, another key aspect of the theory is that goal setting will only be purposeful if people are committed to the goals (Wentzel, 2002). Merely changing employees' behaviour solely by external force is clearly rejected by employees. As a result, decision-makers must adopt a self-management approach to enlist the cooperation of employees and increase their motivation to attain the goals (Erez and Kanfer, 1983). 


\section{Methodology}

In developing the research framework, this study incorporates a model to conceptualise the relationship between the budgetary goal characteristics and budgetary performance. According to the conceptual model, the link between the characteristics of budgetary goals and performance is mediated by the perception of fairness, goal acceptance and goal commitment. The model developed to empirically test such a relationship is depicted in figure 1 in the section - theory development and hypotheses.

The sampling frame was collected from the database provided by the SMI Association of Malaysia, Kuala Lumpur, Malaysia. Also, the respondents represented in the sample design are characterised by those who are in a lower managerial position or a higher position with prior experience in budgeting preparation or who are actively involved in the budgeting process. Selfadministered questionnaires were used for efficiently collecting statistical information from numerous firms. A cover letter was attached to explain the purpose of the study and to assure the respondents' confidentiality in the process of gathering data for the research. The random sampling method was used in this study.

\subsection{Theory development and hypotheses}

This section describes this paper's formation of the variables of interest in the development of the research hypotheses, which were built upon an extensive review of past empirical literature.

\subsubsection{The link between perceived environmental uncertainty (PEU) and budgetary participation}

Based on the contingency theory, a contextual variable, such as environmental uncertainty, is a correlational antecedent of participative budgeting (Birnberg et al., 1990). Gul and Chia (1994) suggested that when PEU is low, management is able to make relatively accurate predictions about the market. However, when PEU is high, management may require additional information to cope with the complexity of the environment. In addition, subordinates can obtain additional job-relevant information through their budgetary participation (Campbell and Gingrich, 1986; Mia, 1987). Thus, this suggests that employees will be keener to participate in information seeking for task completion during periods of high uncertainty. Hence, it is expected that perceived environmental uncertainty is positively associated with budgetary participation. Hypothesis 1 tests for this positive association:

H1: There is a positive significant relationship between perceived environmental uncertainty, namely, state uncertainty, effect uncertainty and response uncertainty, and budgetary participation. 


\subsubsection{The link between budgetary participation and the perception of fairness}

Based on the fairness theory, the concept of distributive fairness stresses that people need to be felt that they have received their fair share of available benefits, i.e. the fair outcome of a discussion or other decision-making process. This is because people place a higher value on their own contribution than the identical contribution of others (Ting and $\mathrm{Yu}, 2010)$. They are highly influenced by the social comparisons of information even in performance situations where objective information is available (Klein, 1977). Thus, it is suggested that by actively participating in the budgetary process, employees are perceived to have a greater opportunity to influence a 'fair' allocation of resources. Hence, it is postulated that distributive fairness should increase with the increased opportunity to gain greater active participation in the process of budget allocations. Hypothesis $2 \mathrm{a}$ tests for this positive association:

$H 2 a$ : Budget participation and the perception of distributive fairness among budgetees (Those involved with a given budget) is positively related.

On the other hand, the concept of procedural fairness stresses that people are perceived to value the fairness of the procedures or processes that are used to arrive at the desired outcomes. People who believe that they have been treated in a procedurally fair manner are more likely to conclude that the resulting outcome is substantively fair. In addition, they are more likely to judge a process as being fair if they are given an opportunity to express their opinion or suggestion. When employees are actively involved in the budgetary process, they can express their stance clearly to the decision-makers, and, in return, they have a better understanding of how budget distributions are determined. Hence, this suggests that employees can gain control over the budgetary process when they actively participate. Hypothesis $2 \mathrm{~b}$ tests for this positive association:

$H 2 b$ : Budget participation and the perception of procedural fairness among budgetees is positively related.

\subsubsection{The link between budgetary feedback and perception of fairness}

In the concept of distributive fairness, a person's perception of 'equitable outcome' is inevitably affected by self-interest or an egocentric bias. People, when probed to determine what amount they should be paid for accomplishing a particular task, expect to be paid substantially more for their own work than they are willing to pay someone else.

In terms of the concept of the perception of procedural fairness, people who believe that they have been treated in a procedurally fair manner are more likely to conclude that the resulting outcome is substantively fair. They care about the consideration that they receive from the decision-makers. In other words, in a process that feels fair, they need to receive assurance that decision- 
makers have listened and understood them, and cared about what they had to say.

Similarly, the effectiveness of feedback, or the extent to which feedback serves motivational and regulatory purposes, can depend on an employee's perception of feedback (Tata, 2002). They will also constantly evaluate the adequacy of outcomes by comparing feedback on these outcomes to the related goals assigned by the organization (Wofford and Goodwin, 1990). When an unexpected discrepancy is indicated by the feedback, employees will either take it positively or negatively. On the positive side, employees may be motivated to change their work behaviour, however, conversely, if employees perceive the feedback to be inaccurate or useless and are dissatisfied with this result, they will tend to ignore such comments and not use the advice they receive (Jawahar, 2010).

Although previous research has not examined the direct relationship between budgetary feedback and the perception of fairness, a few studies have presented mixed results in examining how critical performance reviews influence appraisal reactions (Jawahar, 2010). Thus, it is suggested that when employees receive positive or negative feedback from reviewers, they may or may not support the advice of the reviewer depending on whether or not there is support for their own evaluation. In view of such mixed findings, the nondirectional hypothesis is:

H3: Budgetary feedback relates to the perception of fairness (namely, distributive fairness and procedural fairness).

\subsubsection{The link between budgetary evaluation and the perception of fairness}

In the concept of distributive fairness, a person's perception of the fairness of the outcome is influenced by how they consider they were treated during a dispute resolution or in the decision-making process. If they perceive themselves as treated in a procedurally fair manner, they are more likely to judge the outcome of that process as fair.

In terms of the concept of the perception of procedural fairness, people who believe that they are treated fairly in a decision-making process are more likely to comply with the outcome. This effect will occur even if the outcomes are not personally favourable.

When an evaluation is used effectively, organizational members will have the same frame of reference in respect to performance information, which allows everyone in the organization to interpret the information in the same or a similar manner (Waal, 2004). On the other hand, if the accuracy and legitimacy of the result of the evaluation are weak, an inconsistent and incoherent message will be sent to employees that possibly diminishes the decision's pay-off to certain employees and causes some psychological discomfort (Hanberger, 2011). Thus, the 'satisfaction' of employees has a foundation based upon whether or not the assessment of procedures is fair (Heuer et al., 2007). 
Although no studies have examined this fairness theory relationship, it is assumed that people who are involved in the evaluation process are concerned with maximizing their self-interests (Heuer et al., 2007). When employees feel that they are evaluated unfairly, psychological dysfunction may occur, and it is suggested that for an evaluation to be effective, it should be conducted in accordance with the perceived fairness of the employees affected. Hypothesis 4 tests for this negative association:

H4: Budgetary evaluation and the perception of fairness, namely, procedural fairness and distributive fairness are negatively related.

\subsubsection{The link between the perception of fairness and goal acceptance}

Based on the goal setting theory, goal acceptance is greatly influenced by the degree of the perceived locus of goal setting. This means that people are more likely to accept a goal when it is perceived as being under their control than when it is perceived as externally imposed (Erez and Kanfer, 1983). This is because such controlling power satisfies people's need to feel a sense of mastery and personal competence. Any threat to their sense of control results in reactance or non-compliance. Such explanations can also be included into the theory of fairness. In terms of distributive fairness, people are inevitably affected by self-interest or an 'egocentric bias' when they aim to achieve 'equitable income'. In addition, in procedural fairness, people consider accepting the proposal when they receive assurance that the decision-makers have cared about what they had to say. Research from judicial decision-making has found that the perception of justice is positively related to acceptance of the decision outcome (Renn, 1998). Thus, it is suggested that employees who perceive themselves as being treated fairly tend to demonstrate greater willingness to accept the goals assigned. Thus, it is hypothesized that:

H5: Perception of fairness (namely, procedural fairness and distributive fairness) is positively related to the acceptance of goals.

\subsubsection{The link between the perception of fairness and goal commitment}

In the concept of distributive fairness, when people feel that they are treated in a fair manner, they are more likely to judge the outcome of that process as fair. These people will gradually build a strong attachment with the decision-makers or institutions whereby they will be treated as friends. Ultimately, such a relationship will become beneficial and lead to high individual aspirations and commitment.

In terms of the concept of the perception of procedural fairness, people are more likely to comply with the outcome of the procedure when they believe that they are treated fairly in the decision-making process. Such a perception affects the respect and loyalty of employees' accorded to those decision-makers and the institution that sponsors the decision-making process, as they value a process that treats them with dignity and respect. 
Such explanations of the perception of fairness can also be applied to the goal-setting theory. When employees believe that the outcome of the decisionmaking process is in favour of their personal interests, they will be more likely to commit to the goals, provided that the decision is based upon a fair process. On the other hand, employees perceive a greater chance of success when the distribution of budget resources is adequately allocated. Although the relationship between the perception of fairness and goal commitment has not been examined extensively, the application of the justice of fairness theory to the goal commitment issue suggests a positive relationship (Wentzel, 2002). Thus, it is hypothesized that:

H6: Perception of fairness (namely, procedural fairness and distributive fairness) is positively related to the commitment of goals.

\subsubsection{The link between goal acceptance and budgetary performance}

Based on the goal setting theory, goals will only be accepted by people who are inspired by their own self-set goals, not organizational goals. When such goals are accepted, task performance will also improve for both specific and hard goals. This is because the establishment of such goals is derived from an individual's intention to reach the goals (Erez and Kanfer, 1983). Although no previous study has examined the direct relationship between goal acceptance and budgetary performance from the perspective of management accounting, it is assumed that an individual's accomplishment of the goal must be satisfied before an organization can attain its desired result from budgetary performance. Thus, it is suggested that when employees are willing to accept organizational goals as their own self-set goals, the desired performance will be improved. Thus, it is hypothesized that:

H7: Acceptance of goals is positively related to budgetary performance.

\subsubsection{The link between goal commitment and budgetary performance}

The commitment to budgetary goals is particularly important when the performance of organizations depends largely on the productivity of employees and whether or not they can achieve the company objectives. The goal setting theory assumes that individuals will be committed when they are assigned goals. It is evident that employees improve their performance when they accept and commit to attain a particular goal (Wentzel, 2002). On the other hand, if employees are not committed to the goals, there will not only be a low productivity level but also increased employee resistance to change (Locke and Laham, 1990). Thus, it is suggested that when employees are committed to budgetary goals, the performance will be improved for the organization. Thus, it is hypothesized that:

H8: Commitment of goals and budgetary performance are positively related. 


\subsection{Conceptual model}

The resulting model's justification, description, and explanation (Figure 1) and its presumed relationship with other constructs, are presented below. The model illustrates the links between the constructs. This model comprises six main elements: budgetary participation, budgetary feedback, budgetary evaluation, perception of fairness, goal acceptance and goal commitment.

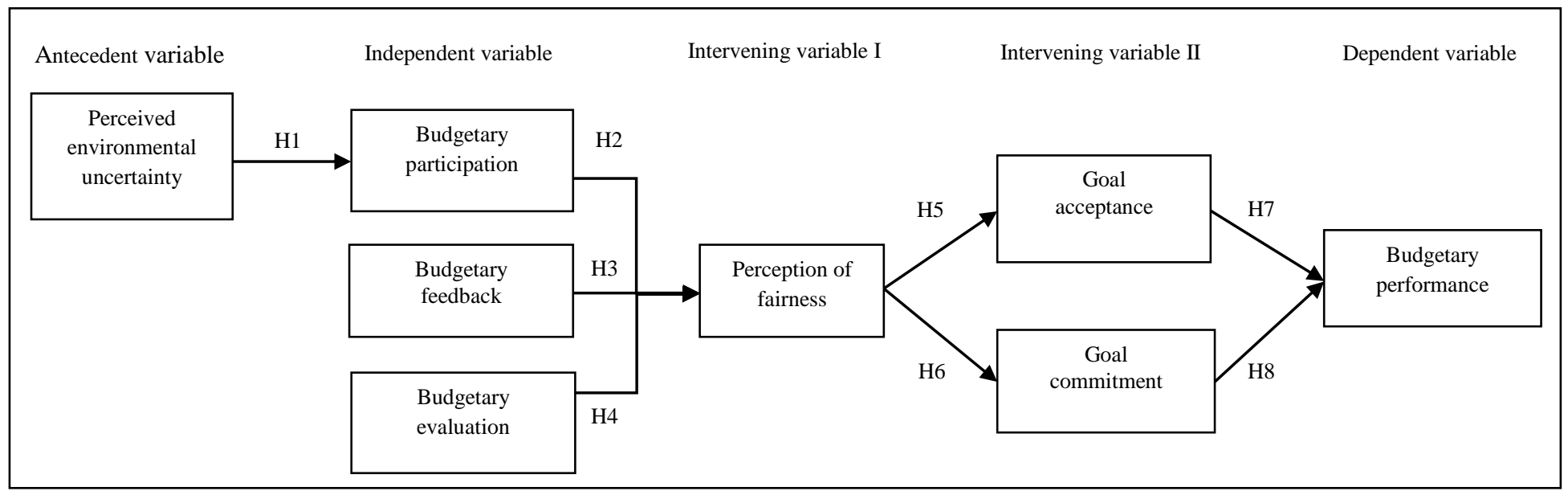

Figure 1: Research model and proposed hypotheses 


\section{Discussion}

Many organizations are unaware of the importance of having proper budgetary goals that can accurately reflect their financial position. Camino and Cardone (1999) explained that many organizations fail to prepare detailed working papers attached to the budget plan and projected cash flow statement, when they apply for loans. Thus, organizations face difficulty in obtaining funds from financial institutions and the government.

In particular, they fail to understand the importance of using budgetary reports for decision-making and resource allocation to reduce uncertainty in their decision-making (Shahwan and Al-Ain, 2008). Shahwan and Al-Ain (2008) indicated that most small companies do not find the budgetary information useful or that they are lacking proper budgetary controls in their system design. They even pointed out that only a very small percentage of companies prepare such information for the use of decision-making and for long term strategy planning. Thus, such inefficiency or poor managerial ability leads to the poor growth of an organization (Barker, 2003). As a result, management has to improve the effectiveness and efficiency of the business activities.

Although many managers in this survey claimed that they can obtain the budgetary information easily, there is still a doubt as to whether managers have a good understanding of the available budgetary information and how it should be used in decision-making, as the data contributes to the success or failure of the companies (El Luodi, 1998). Thus, the level of awareness of understanding the importance of budgetary goals in determining a firm's overall performance, lay in the successful use of the budgeting process.

\section{Conclusions}

The contributions from this study are discussed from the theoretical, methodology and practical perspectives. Theoretically, the contribution of this study to the knowledge contained in the existing literature is three-fold.

Firstly, the study found that task uncertainty is an important antecedent of budgetary participation. Employees who are low in budgetary analysis skills tend to participate more in the budgeting process when they require additional job-relevant information.

Secondly, participation in setting the budget influences a subordinate's budget goal levels and motivation (i.e. budget goal acceptance and budget goal commitment), which, ultimately, enhances their job performance. The study provided evidence that the perception of fairness mediates the relation between the levels of budget participation and goal commitment, in which goal commitment mediates the relation between the perception of fairness and performance.

Thirdly, participation affects performance through its effect on goal acceptance, and, from this, performance also increases. Participation in goal 
setting enhances goal acceptance when presenting individuals with goals that they initially reject because they perceive them as being unreasonable or too difficult.

Lastly, many organizations should strive to maximize the effectiveness and efficiency in the budgetary controlling process in order to maintain their competitive advantage. This is because having a proper budgetary control system allows companies to improve their managerial attitude and performance, and provides these organizations with useful information to tackle their daily financial challenges.

\section{Acknowledgment}

This research is funded by the University of Malaya under the Exploratory Research Grant Cluster Scheme (ERGS).

\section{References}

Barker, R. (2003). The Revolution Ahead in Financial Reporting: Reporting Financial Performance. Balance Sheet, 11(4): 19-23.

Birnberg, J.C. Shields, M.D. and Young, S.M. (1990). The Case for Multiple Methods in Empirical Management Accounting Research: With an Illustration from Budget Setting. Journal of Management Accounting Research: 33-66.

Camino, D. and Cardone, C. (1999). The Valuation and Cost of Credit Issuance Schemes for SMEs: The Role of the Loan Guarantee Association. International Small Business Journal, 17(44): 13-31.

Campbell, D.J. and Gingrich, K.F. (1986). The Interactive Effects of Task Complexity and Participation On Task Performance: A Field Experiments. Organisational behaviour and Human Decision Processes: 162-180.

Chong, V.K. and Johnson, D.M. (2007). Testing A Model of Antecedents and Consequences of Budgetary Participation On Job Performance. Accounting and Business Research, 31(1): 3-19.

El Luodi, M. (1998). The relationship among organisation structure, information technology and information processing in small Canadian firms. Canadian Journal of Administrative Sciences, 15(2): 180-199.

Erez, M. and Kanfer, F.H. (1983). The Role of Goal Acceptance in Goal Setting and Task Performance. The Academy of Management Review, 8: 454-463.

Gul, F.A. and Chia, Y.M. (1994). The Effects of Management Accounting Systems, Perceived Environmental Uncertainty and Decentralisation On Managerial Performance: A Test of Three-Way Interaction. Accounting, Organisations and Society, 19: 413-426.

Hanberger, A. (2011). The Real Functions of Evaluation and Response Systems. Evaluation, 17: 327-349.

Hansen, S. C. and Stede, W. A. (2004). Multiple Facets of Budgeting: An Exploratory Analysis. Management Accounting Research, 15: 415-439. 
Heuer, L., Penrod, S. and Kattan, A. (2007). The Role of Societal Benefits and Fairness Concerns Among Decision Makers and Decision Recipients. Law Human Behaviour, 31: 573-630.

Jawahar, I.M. (2010). The mediating role of appraisal feedback reactions on the relationship between rater feedback-related behaviour and rate performance. Group and Organization Management, 35(4): 494-526.

Jermias, J. and Setiawan, T. (2008). The Moderating Effects of Hierarchy and Control Systems On the Relationship Between Budgetary Participation and Performance. The International Journal of Accounting, 43: 268-292.

Kenis, I. (1979). Effects of Budgetary Goal Characteristics On Managerial Attitudes and Performance. The Accounting Review, 10(40): 707-721.

Locke, E.A. and Lantham, G.P. (1990). A Theory of Goal Setting and Task Performance. Eagewood Cliffs, New Jersey: Prentice Hall.

Mohamed Yunos, R., Ismail, Zubaidah., Smith, M., (2012). Ethnicity and Accounting Conservatism: Malaysian Evidence. Asian Review of Accounting, 20(1): 34-57.

Mia, K. (1987). Participation in Budgetary Decision-Making, Task Difficulty, Locus of Control and Employee Behaviour: An Empirical Study. Decision Science, 18: 547-561.

Nouri, H. and Parker, R. (1998). The Relationship Between Budget Participation and Job Performance: The Roles of Budget Accuracy and Organisational Commitment. Accounting, Organisations and Society, 25: 5-6.

Renn, R.W. (1998). Participant's Effect On Task Performance: Mediating Roles of Goal Acceptance and Procedural Justice. Journal of Business Research, 41: $115-125$.

Shahwan, Y. and Al-Ain (2008). Qualitative Characteristics of Financial Reporting: A Historical Perspective. Journal of Applied Accounting Research, 9(3): 192-202.

Tata, J. (2002). The Influence of Managerial Accounts On Employees' Reactions to Negative Feedback. Group and Organisation Management, 27: 480-503.

Ting, C.Y, and Yu, T. K. (2010). Modelling Patient Perceptions of Service Recovery: The Effects of Perceived Fairness On Health Center Repatronage. Social Behaviour and Personality, 38(3): 395-404.

Tsui, J. (2001). The Impact of Culture On the Relationship Between Budgetary Participation, Management Accounting Systems, And Managerial Performance: An analysis of Chinese and Western managers. The International Journal of Accounting, 36: 125-146.

Waal, A.A. (2004). Stimulating Performance-Driven Behavior to Obtain Better Results. International Journal of Productivity and Performance Management, 53(4): 301-306.

Wentzel, K. (2002). The Influence of Fairness Perceptions and Goal Commitment On Managers' Performance in A Budget Setting. Behavioral Research in Accounting, 24: 247-271. 
Wofford, J.C. and Goodwin, V.L. (1990). Effects of Feedback On Cognitive Processing and Choice of Decision Style. Journal of Applied Psychology, 75(6): 603-612. 